\title{
O processo de ensino-aprendizagem de puérperas nutrizes sobre aleitamento materno
}

\author{
The teaching-learning process of puerperal mothers on breastfeeding
}

\section{El proceso de enseñanza-aprendizaje de puérperas que amamantan sobre lactancia materna}

\author{
Andréa Lyra Arnozo da Rocha ${ }^{1}$, Fernanda Garcia Bezerra Góes ${ }^{2}$, Fernanda Maria Vieira Pereira ${ }^{3}$,

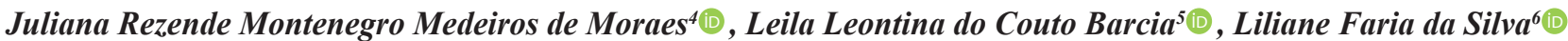

\section{Histórico}

Recibido:

02 de febrero de 2018

Aceptado:

11 de abril de 2018

1 Acadêmica de Enfermagem. Universidade Federal Fluminense. Rio das Ostras, Brasil.

2 Doutora em Enfermagem. Docente do Departamento de Enfermagem de Rio das Ostras da Universidade Federal Fluminense. Rio das Ostras, Brasil. Autor de Correspondência. E-mail: ferbezerra@gmail.com

3 Doutora em Enfermagem. Docente do Departamento de Enfermagem de Rio das Ostras da Universidade Federal Fluminense. Rio das Ostras, Brasil.

4 Doutora em Enfermagem. Docente do Departamento de Enfermagem Materno-Infantil da Escola de Enfermagem Anna Nery da Universidade Federal do Rio de Janeiro. Rio de Janeiro, Brasil.

5 Doutora em Enfermagem. Docente do Departamento de Enfermagem de Rio das Ostras da Universidade Federal Fluminense. Rio das Ostras, Brasil.

6 Doutora em Enfermagem. Docente do Departamento de Enfermagem Materno-Infantil e Psiquiátrica da Escola de Enfermagem Aurora de Afonso Costa da Universidade Federal Fluminense. Niterói, Brasil.
Introdução: A prática educativa no puerpério sobre aleitamento materno deve estar inserida no fazer dos profissionais de saúde, incluindo o enfermeiro. Nessa perspectiva, o estudo objetivou descrever o processo de ensino-aprendizagem relacionado ao aleitamento materno de puérperas nutrizes. Materiais e Métodos: Pesquisa qualitativa, desenvolvida em 2017, através do método criativo sensível, junto a 08 puérperas no Alojamento Conjunto de um hospital municipal de Rio das Ostras, Brasil, cujos dados foram submetidos à análise temática. Resultados: O processo de ensino-aprendizagem foi permeado pela influência de mulheres da família e de outras gestantes, além de profissionais de saúde, particularmente de enfermeiras do hospital. Nessas relações, o aprendizado foi sobre importância da amamentação, qualidade do leite materno, posicionamento do bebê e manejo das mamas. A mediação de saberes ocorreu por experiências prévias, além de orientações profissionais através de estratégias verbais e demonstrativas. Discussão: As enfermeiras do hospital são as profissionais que frequentemente orientam e apoiam o aleitamento materno. Conclusões: É preciso avançar em ações educativas em saúde sobre a temática, especialmente a partir do conhecimento anterior das puérperas.

Palavras chave: Aleitamento Materno; Educação em Saúde; Período Pós-Parto.

Abstract

Introduction: The puerperal educational practice on breastfeeding should be part of the work of health professionals, including nurses. Within this perspective, the study sought to describe the teaching-learning process related to breastfeeding of puerperal mothers. Materials and Methods: Qualitative research, conducted in 2017, through the sensitive creative method, together with eight puerperal women in the Joint Housing of a municipal hospital in Rio das Ostras, Brazil, whose data were submitted to thematic analysis. Results: The teaching-learning process was permeated by the influence of women from the family and from other pregnant women, in addition to health professionals, particularly hospital nurses. In these relationships, learning was about the importance of breastfeeding, quality of breast milk, positioning of the baby, and breast management. Mediation of knowledge occurred through prior experiences, as well as professional guidance through verbal and demonstrative strategies. Discussion: Hospital nurses are the professionals who frequently guide and support breastfeeding. Conclusions: It is necessary to advance in educational actions in health on the theme, especially from the previous knowledge of the puerperal women.

Key words: Breast Feeding; Health Education; Postpartum Period.

Resumen

Introducción: La práctica educativa en el puerperio sobre la lactancia materna debe estar incorporada en el hacer de los profesionales de salud, incluyendo el enfermero. En esta perspectiva, el objetivo del estudio fue describir el proceso de enseñanza-aprendizaje relacionado a la lactancia materna de puérperas en periodo de lactación. Materiales y Métodos: Investigación cualitativa, desarrollada en 2017, a través del método creativo sensible, junto a 08 puérperas en el Alojamiento Conjunto de un hospital municipal de Rio de las Ostras, Brasil, cuyos datos se sometieron al análisis temático. Resultados: El proceso de enseñanza-aprendizaje fue impregnado por la influencia de mujeres de la familia y de otras gestantes, además de profesionales de la salud, particularmente de enfermeras del hospital. En estas relaciones, el aprendizaje fue sobre la importancia de la lactancia materna, la calidad de la leche materna, el posicionamiento del bebé y el manejo de las mamas. La mediación de saberes ocurrió por experiencias previas, además de orientaciones profesionales a través de estrategias verbales y demostrativas. Discusión: Las enfermeras del hospital son las profesionales que con frecuencia orientan y apoyan la lactancia materna. Conclusiones: Es necesario avanzar en acciones educativas en salud sobre la temática, especialmente a partir del conocimiento anterior de las puérperas.

Palabras clave: Lactancia Materna; Educación en Salud; Periodo Posparto.

Como citar este artigo: Rocha ALA, Góes FGB, Pereira FMV, Moraes JRMM, Barcia LLC, Silva LF. O processo de ensino-aprendizagem de puérperas nutrizes sobre aleitamento materno. Rev Cuid. 2018; 9(2): 2165-76. http://dx.doi.org/10.15649/cuidarte.v9i2.510

(1) (1) (9) 2018 Universidad de Santander. Este es un artículo de acceso abierto, distribuido bajo los términos de la licencia Creative Commons Attribution (CC BY-NC 4.0), que permite el uso ilimitado, distribución y reproducción en cualquier medio, siempre que el autor original y la fuente sean debidamente citados. 


\section{INTRODUÇÃO}

No puerpério imediato e tardio, período de tempo compreendido entre o nascimento do neonato e o $10^{\circ}$ dia e $45^{\circ}$ dia de pós-parto, respectivamente, muitas mudanças ocorrem na vida do bebê, da mãe e da família. Nesse momento, muitas mulheres possuem dúvidas e receios inerentes à amamentação, logo, os profissionais de saúde, incluindo os enfermeiros, precisam realizar práticas educativas contextualizadas sobre a temática. Tais orientações visam, dentre outros aspectos, promover o aleitamento materno exclusivo (AME) até o sexto mês de vida e de forma complementar até dois anos, conforme preconiza o Ministério da Saúde (MS) e a Organização Mundial da Saúde (OMS) ${ }^{1}$.

Sabe-se que o processo de ensino-aprendizagem relacionado à amamentação nos serviços de saúde deve ser anterior ao puerpério, ainda no pré-natal, de modo que haja o incremento da prevalência do aleitamento materno no Brasil e, por conseguinte, a redução da morbimortalidade infantil e materna, dado o caráter protetor da amamentação contra diversos agravos ${ }^{2}$.

Logo, existem diferentes estratégias que visam apoiar, promover e proteger essa prática, objetivando tornar a amamentação uma prática consciente, para que tanto a puérpera como sua família sejam capazes de tomar decisões mais assertivas e seguras. Dentre elas, o Programa Nacional de Incentivo ao Aleitamento Materno, a Rede Brasileira de Bancos de Leite Humano, a capacitação de profissionais da Atenção Básica, a Iniciativa Hospital Amigo da Criança, a Norma
Brasileira para Comercialização de Alimentos para Lactentes e Crianças de Primeira Infância, Bicos, Chupetas e Mamadeiras, além da Semana Mundial da Amamentação ${ }^{3}$.

Contudo, a II Pesquisa de Prevalência do Aleitamento Materno nas Capitais Brasileiras e Distrito Federal aponta que a taxa entre crianças menores de 6 meses é de $41 \%$, sendo um indicador razoável e insatisfatório, segundo a OMS, já que para ser considerado "Muito Bom" este indicador deveria estar entre 90 e $100 \%{ }^{2}$.

Nessa perspectiva, evidências científicas apresentam questões sociais, econômicas e afetivas relevantes sobre os fatores que influenciam a autoeficácia materna em amamentar e o conhecimento de puérperas sobre amamentação, contudo, não identificam com clareza de que forma estes conhecimentos e práticas surgem, evidenciando uma lacuna do conhecimento, o que justificou a realização do presente estudo.

Dessa forma, objetivou-se descrever o processo de ensino-aprendizagem relacionado ao aleitamento materno de puérperas nutrizes.

\section{MATERIAIS E MÉTODOS}

Pesquisa qualitativa, desenvolvida por meio do método criativo sensível (MCS), que utiliza a arte como ferramenta para a expressão livre de situações existenciais, criando espaços para discussão e reflexão mediados pelo diálogo, nos quais os indivíduos problematizam práticas vivenciais e existenciais ${ }^{4}$. Para a descrição 
da pesquisa foram adotados os Critérios Consolidados de Relatos de Pesquisa Qualitativa $(\mathrm{COREQ})^{5}$.

A produção de dados aconteceu de maio a junho de 2017, no Alojamento Conjunto de um hospital municipal localizado em Rio das Ostras no estado do Rio de Janeiro, junto a mulheres maiores de 18 anos em puerpério imediato que estavam amamentando seus filhos em boas condições de saúde, internadas no Alojamento Conjunto, sendo estes os critérios de inclusão do estudo. Excluíram-se as que apresentaram intercorrências clínicas no momento da produção de dados; que tinham limitação cognitiva e mental; e as com filhos internados no Berçário. As mulheres, que atendiam aos critérios de inclusão, foram abordadas pessoalmente pela primeira pesquisadora e convidadas a participarem da pesquisa. Algumas puérperas, que relataram cansaço, recusaram a participação. Contudo, dentre as participantes que aceitaram, não houve desistência.

De acordo com as diretrizes do MCS, utilizouse a dinâmica de criatividade e sensibilidade (DCS) intitulada "Linha da Vida". Esta técnica permite ao pesquisador observar o objeto por uma perspectiva histórico-social, uma vez que estimula a socialização de experiências e vivências adquiridas ao longo da vida ${ }^{4}$.

A DCS ocorreu a partir de oficinas com as puérperas, as quais, depois de informadas sobre o funcionamento da dinâmica, as mesmas se utilizaram de materiais como folhas A4 coloridas, caneta hidrocor, revistas, jornais, tesoura e cola para expressar, como considerassem mais conveniente, suas vivências quanto à amamentação a partir da seguinte questão geradora de debate (GGD): O que, com quem e como você aprendeu sobre amamentação ao longo da sua vida?

Posteriormente, as participantes anexaram suas produções artísticas na Linha da Vida, especificamente nas fases da vida (infância, adolescência/juventude e fase adulta) que julgaram ser a origem temporal do aprendizado. A fim de assegurar a confiabilidade dos dados, o registro das falas ocorreu através de gravação por mídia digital.

A DCS desenvolveu-se em cinco momentos, a saber: no $1^{\circ}$ momento fez-se a organização do ambiente e o acolhimento das participantes; no $2^{\mathrm{o}}$ momento os materiais foram disponibilizados, a QGD apresentada oralmente e por escrito e as produções artísticas elaboradas; no $3^{\circ}$ momento cada participante apresentou ao grupo o material produzido individualmente e a pesquisadora registrou os assuntos convergentes e divergentes, dos quais foram codificados os temas geradores. No $4^{\circ}$ momento, da análise coletiva e discussão grupal, os temas geradores foram decodificados em subtemas; e, por fim, no $5^{\circ}$ momento realizouse a síntese temática dos temas e subtemas e a validação dos dados pelas próprias participantes ${ }^{4}$.

Todas as etapas aconteceram concomitantemente no interior de cada dinâmica. Para isso, além da pesquisadora, primeira autora, acadêmica de enfermagem que foi treinada pela orientadora para atuar como animadora do grupo, uma 
auxiliar de pesquisa, a professora doutora em enfermagem, segunda autora, que tem experiência com a condução da dinâmica de criatividade e sensibilidade, fez anotações de tudo que observava, controlando o gravador de áudio e ainda fazendo registros fotográficos (apenas das produções artísticas). Destaque-se que estavam presentes no momento da dinâmica apenas as pesquisadoras e as puérperas, sendo assim, garantida a privacidade das participantes.

Utilizou-se como critério para o encerramento do trabalho de campo a amostragem por saturação teórica, a partir da recorrência de ideias, práticas e visões de mundo sobre a temática nas dinâmicas ${ }^{6}$.

Os dados foram submetidos à análise temática, seguindo suas três etapas, a saber: a préanálise, momento da leitura flutuante, por meio de um contato intenso do pesquisador com o conteúdo; a exploração do material, na qual o conteúdo foi categorizado, por meio de marcação colorimétrica, gerando palavras significativas em torno das quais as falas foram organizadas, e com a redução do texto em expressões relevantes; o tratamento dos dados obtidos e interpretações, com inferências e interpretações ${ }^{7}$.

A pesquisa seguiu as determinações da Resolução n 466 de 12 de dezembro de 2012 do Conselho Nacional de Saúde, sendo aprovada pelo Comitê de Ética (CAAE: 64106016.4.0000.5243, n. ${ }^{\text {o }}$ Parecer: 2.064.418). As participantes foram informadas quanto ao anonimato com o uso de um código alfanumérico (M1, M2, M3 e assim por diante), participação voluntária e ausência de riscos físicos, culminando com a assinatura do Termo de Consentimento Livre e Esclarecido.

\section{RESULTADOS}

Participaram oito puérperas nutrizes, organizadas em 3 grupos de 2 a 3 participantes, com idades entre 18 e 39 anos; apenas 4 delas pariram seus bebês por parto vaginal. Quanto aos neonatos, 5 eram do sexo masculino e 3 do sexo feminino; apenas um deles foi considerado pequeno para a idade gestacional; e 2 dos bebês não estavam em aleitamento materno exclusivo.

A partir da Análise Temática dos dados emergiram as seguintes unidades temáticas: os participantes do processo de ensino-aprendizagem sobre aleitamento materno; os conteúdos do processo de ensino-aprendizagem sobre aleitamento materno; e, a mediação de saberes no processo de ensino-aprendizagem sobre aleitamento materno.

\section{Os participantes do processo de ensino- aprendizagem sobre aleitamento materno}

As puérperas, ao falarem a respeito das pessoas que participaram do seu processo de ensinoaprendizagem sobre aleitamento materno, destacaram a família, sobretudo as mulheres, de diferentes gerações, a saber, avó, mãe, tia, irmã, cunhada, sogra e madrasta. 
“Eu aprendi com a minha mãe, minhas irmãs.” (M2)

"Ela [mãe] sempre cuidou bem da gente, sempre mostrou como que se alimenta. Tanto é que quando eu tive [...] minha primeira filha, eu estou amamentando direitinho.” (M5)

"Tudo que minha avó falava, eu via minha mãe botando em prática com meu irmão caçula. [...] Muita coisa minha mãe está me ajudando. [...] Sem ela, acho eu não saberia o que fazer.” (M4)

"Vivi de forma direta a experiência do aleitamento materno com a minha madrasta, cuidando do meu irmão." (M6)

Nas falas das participantes, a figura familiar da mulher é majoritária no que tange a influência sobre as questões relativas ao aleitamento materno, na medida em que o homem foi destacado apenas por uma puérpera:

“Tem meu pai, meu pai me apoia muito.” (M5)

Dentre os diferentes profissionais de saúde citados como mediadores no processo de ensinoaprendizagem observa-se, no relato da maioria das puérperas, a predominância das enfermeiras que atuam em diversos contextos, como o pré-natal e palestras em igrejas. Todavia, houve destaque para as enfermeiras atuantes no hospital.

"Aqui no hospital a enfermeira fala mais. Sempre aparecem [...] no hospital [...] onde a gente ganha [o bebê]. Elas são o incentivo maior pra gente amamentar.” (M1)

“As enfermeiras [...] do hospital onde eu ganhei. [...] Em Rio das Ostras e na Bahia.” (M2) "Eu aprendi foi nessa primeira gestação [...] que eu assisti a uma palestra na minha igreja [...] com uma enfermeira. Eu gostei muito. [...] Ela interage com as pessoas." (M7)

As enunciações das puérperas reforçam que no hospital, cenário da pesquisa, a enfermeira ensina conteúdos relacionados ao aleitamento materno junto às puérperas.

"O que eu sei, eu aprendi aqui [no hospital] agora, [...] com as enfermeiras." (M3)

"As enfermeiras daqui do hospital mesmo. [...] Eu não tinha noção como amamentar." (M4)

Os demais profissionais citados foram o fonoaudiólogo, o fisioterapeuta e o médico pediatra. Segundo as participantes, a equipe de saúde apoia e orienta o aleitamento materno. 
“Até o pediatra também orienta.” (M1)

“Aprendo [...] com uma pessoa que me apoia, [...] uma fisioterapeuta." (M6)

"Lendo e conversando com as pessoas. [...] Eu aprendi mesmo até com a fono daqui [...] que me orientou." (M8)

Ao longo da gestação atual e de gestações anteriores, duas puérperas alegaram construir uma rede de apoio com outras gestantes, o que permitiu a troca de experiências, baseada na conversa, com a socialização de conhecimentos marcantes para elas, como pode ser expresso pelas falas:

"Você vai num grupo e não conhece ninguém. [...] É muito bom quando você está grávida, ai você senta junto com uma pessoa e conhece aquela grávida. [...] Troca ideia com ela, experiência da gravidez dela e você conta da sua. Você monta o ciclo." (M7)

"Conversei até mesmo nas consultas [...]. A gente acaba conhecendo muitas [gestantes]. A gente conversou bastante [...] sobre amamentação.” (M8)

E ainda, uma das participantes relatou que por meio de pesquisas na internet tomou conhecimento de um canal em um site de vídeos, idealizado por uma enfermeira, no qual ela aprendeu a respeito de vários assuntos relacionado à amamentação e cuidados com o recém-nascido e passou a válido.

“Também procuro pela internet porque [...] te ensina coisas muito legais. [...] Eu uso pra mim e [...] indico. [...] Tem um canal [de uma enfermeira] que ensina tudo em detalhes sobre amamentação.” (M6)

\section{Os conteúdos do processo de ensino-aprendizagem sobre aleitamento materno}

A partir do compartilhamento das experiências na trajetória de suas vidas, as puérperas revelaram os conteúdos que mais marcaram seu aprendizado. Questões relacionadas à importância da amamentação, à qualidade do leite materno, ao posicionamento que mais favorece a prática do aleitamento materno, aos cuidados gerais e ao manejo das mamas emergiram das lembranças compartilhadas nas dinâmicas.

Em seu relato, a puérpera M2 afirmou ter aprendido com sua família que a amamentação é importante para o bebê porque aumenta a proximidade entre mãe e filho, como se observa em sua fala:

“Fica mais próximo do filho [...] e que amamentar é importante pra saúde do bebê.” (M2)

No relato das puérperas, percebe-se a apreensão do conhecimento de ofertar somente leite materno até os seis meses e alcançar dois anos de idade do bebê, de modo complementar: 
"[Amamentar] até os seis meses." (M8)

"De quanto é importante a amamentação até os dois anos de idade." (M7)

A valorização da amamentação também pode ser verificada nos depoimentos que seguem:

"Que amamentar é a parte mais importante para o bebê. (...) Que se botar outros leites [...] não é tão importante como a da amamentação materna." (M1)

"A amamentação é a fase mais importante na vida do bebê, pois o leite é rico em nutrientes." (M7)

Seis puérperas relataram orientações e/ou demonstrações realizadas, por enfermeiras, sobre o posicionamento e a pega para amamentar o bebê de forma eficiente.

“A enfermeira daqui [...] fala da posição que a gente tem que amamentar.” (M1)

"[A enfermeira do hospital] ensinou como que coloca o bebê para amamentar, [...] a posição.

Que o narizinho tem que ficar encostado e a parte escura todinha na boca dele." (M7)

O relato da puérpera M1 explicitou que no pré-natal foi abordada a importância da amamentação sem, contudo, serem detalhadas questões práticas a respeito da amamentação.

"[No pré-natal] falaram que é importante também, só que não ensina a gente. [...] Aqui no hospital é diferente. [...] Porque aqui ensina. Pega o bebê, coloca." (M1)

Especificamente sobre cuidados com as mamas, alguns depoimentos referem à atuação da enfermeira e de outros profissionais da saúde, mostrando que as participantes guardaram consigo os possíveis cuidados com as mamas que podem prevenir problemas futuros.

"Ela [a enfermeira do hospital] falou que tem que tomar sol, cuidar bastante do bico do peito para o neném não machucar na hora de mamar.” (M7)

"Aprendi [com as enfermeiras] que é mito que eles falam que não pode arrotar no peito que racha." (M8)

\section{A mediação de saberes no processo de ensino-aprendizagem sobre aleitamento materno}

A mediação de saberes ocorreu por meio de experiências diretas e na família; orientação, apoio e incentivo verbal à prática do aleitamento materno; e por ações demonstrativas.

As vivências relativas à amamentação se mostraram marcantes na vida das puérperas e ocorreram de duas maneiras, quando as mesmas foram amamentadas em seus primeiros anos de vida e/ou quando na juventude e fase adulta amamentaram seus próprios bebês. Cumpre destacar que todas as puérperas, durante as dinâmicas, demonstraram desejo em amamentar. 
"Meu irmão mamava muito. Então, quase sempre eu via mamando. [...] Ele mamou até uns quatro anos de idade. [...] Meus irmãos já pegavam direto [no peito]. Ele [o bebê] não, ele demora, fica, bota, suga três vezes [...] e fico agoniada. Eu quero amamentar, não quero mais que ele tome [...] esses leites." (M4)

"Minha mãe lavava roupa para fora. Ai quando ela chegava, eu ia correndo atrás dela para mamar. Ai meus irmãos ficavam falando que eu já era grande, que não era para mamar mais. [...] Eu mamei até quatro anos. [...] E os meus dois filhos, eu amamentei até dois anos. ” (M2)

As puérperas também aprendem observando as reações do próprio bebê durante a amamentação e afirmam receber deles uma grande ajuda, o que pode ser verificado nestes relatos:

"Ele [o bebê] está me ensinando, porque se eu boto numa posição ruim ele reclama, sente desconforto. Então ele está ensinando também a melhor forma de ajudar ele mesmo.” (M4) "Minha filha [a bebê] também tem me ajudado." (M5)

Outra abordagem que resultou em aprendizado foram as estratégias verbais de orientação direcionadas às puérperas, utilizadas pela família, enfermeiras, outros profissionais de saúde, outras mães e gestantes e a internet.

"As enfermeiras falam da posição [...]. O médico fala como cuidar e [...] da importância que tem da mama." (M1)

“A minha cunhada e eu conversamos muito, ela sempre também me explicou.” (M5)

"A fono [fonoaudióloga] é uma pessoa que [...] orienta." (M6)

"A enfermeira interage com as pessoas e com o grupo e ela falou de amamentação." (M7)

Ademais, todas as puérperas indicaram terem assistido ou participado de demonstrações sobre amamentação, particularmente no hospital, e destacaram a importância dessa estratégia para o seu aprendizado.

“As enfermeiras ensinam [...]. Elas pegam o bebê para ensinar. [...] Colocar no seio.” (M1) “A enfermeira mexeu, fez o bico, levou ele [o bebê ao seio].” (M3)

"Posicionando ele certinho no peito, mostrando como deve segurar a mama para pode não prende o leite." (M4)

"Eu me lembro da palestra que foi até mostrando os nenenzinhos chupando o peito e tal. Falando sobre amamentação, dessa parte escura dos peitos." (M8) 


\section{DISCUSSÃ̃O}

Os resultados da pesquisa mostraram que mulheres de diferentes gerações participam do processo de ensino-aprendizagem sobre aleitamento materno das puérperas nutrizes. Tal achado vai ao encontro de estudo que refere que as mulheres da família exercem influência decisiva no aconselhamento, apoio e cuidado à puérpera e ao recém-nascido. Nessa perspectiva, observa-se que ainda existe um domínio feminino na esfera da reprodução, contudo, acredita-se que mudanças estão ocorrendo para uma maior participação masculina ${ }^{8}$.

No que se refere à participação dos profissionais de saúde, foi expressiva a atuação das enfermeiras, especialmente do hospital. Este dado é contraditório aos achados de um estudo com 16 mulheres, no qual apenas duas participantes se pronunciaram positivamente com relação à ajuda da enfermeira em relação à prática do aleitamento materno ${ }^{9}$.

No puerpério dúvidas, medos e dificuldades em amamentar surgem com muita frequência, logo, o enfermeiro, por estar muito próximo à mulher neste período, deve exercer um papel fundamental de educador em saúde. É essencial ouvir a puérpera para conhecer o que ela sabe a respeito de amamentação e, numa relação baseada na conversa e respeito, fazer as devidas orientações $^{10}$.

Houve pouca expressividade da atuação do médico, nas falas das participantes. Tal achado é divergente a outro estudo no qual este profissional foi o que mais se destacou quanto à abordagem sobre aleitamento materno exclusivo ${ }^{11}$.
Estudo cujo objetivo foi conhecer a rede de apoio social das puérperas na prática da amamentação revelou que as experiências de terceiros também foram significativas para as mesmas durante o período da amamentação ${ }^{12}$. Este dado reafirma os achados desta pesquisa no tocante à importante troca de experiências entre mulheres puérperas, gestantes e mães, apontada pelas participantes, onde todas ensinam e aprendem em um processo dialógico. O que corrobora com os pressupostos de que as pessoas se educam em comunhão, mediatizadas pelo mundo ${ }^{13}$.

Neste sentido, quem ensina aprende ao ensinar e quem aprende ensina ao aprender, logo, do ponto de vista democrático, ensinar inexiste sem aprender e vice-versa ${ }^{13}$. Nessa lógica, apesar dos resultados da pesquisa focar, majoritariamente, no aprendizado das nutrizes, participantes do estudo, sobre aleitamento materno, a prática educativa em si, que envolveu educadores e educandos (nutrizes, mulheres da família e do meio social e profissionais de saúde), pressupõe interação mediada por ensino e aprendizagem entre os envolvidos, pois todos os sujeitos aprendem e ensinam, independente desse reconhecimento.

As tecnologias da informação permitem a extensão rápida de conhecimentos à lugares remotos, corroborando com o achado deste estudo. Verifica-se, portanto, que os profissionais da enfermagem têm alcançado, por meios digitais, gestantes e mães, favorecendo a educação em saúde na construção de conhecimentos inerentes ao aleitamento materno ${ }^{14}$.

É preciso considerar que a Enfermagem tem o importante papel de incentivar a amamentação, transmitindo confiança, para que as mulheres tenham mais chance de alcançar sucesso na prática 
do aleitamento materno ${ }^{15}$. Tais considerações corroboram com a recorrência das enfermeiras nas vozes das puérperas nutrizes.

Uma gama de aprendizados, seja pelas orientações ou pelas próprias vivências, permeou o processo de ensino-aprendizagem das puérperas no que tange o aleitamento materno. Destaca-se que as experiências diretas com o próprio filho também promoveram aprendizado, o que reforça que os indivíduos aprendem a partir da realidade vivida, por vezes, mais do que a mera transmissão de conteúdos por um educador, logo, ensinar não é transferir conhecimento e sim criar possibilidades para a sua própria construção ${ }^{13}$.

Nessa perspectiva, as nutrizes possuem um corpo de conhecimentos, construído em suas experiências de vida, e assim, elas também são detentoras de saberes singulares sobre o aleitamento materno, sendo capazes de aprender e de ensinar, o que impõe a necessidade do respeito à dignidade, à autonomia e à identidade do educando ${ }^{13}$.

Com relação aos conteúdos apreendidos, os achados do estudo apontaram a compreensão da importância na proximidade mãe-filho, o que vai ao encontro de um estudo que destacou que as puérperas acreditam que a prática de aleitamento materno exclusivo favorece o estreitamento dos laços afetivos entre mãe e filho, e que a proteção conferida à criança através do leite materno traz benefícios para ela e sua família ${ }^{15}$.

Algumas puérperas nutrizes destacaram a aprendizado sobre a manutenção do aleitamento materno por seis meses de modo exclusivo e dois anos complementar, o que corrobora com outro estudo no qual nenhuma mãe apresentou baixa autoeficácia no tipo de dieta da criança, pois todas mostraram ter ciência sobre o período indicado para a amamentação ${ }^{16}$.

As depoentes falaram ainda da importância de ter acesso a informações e explicações de mais modo prático. Nesse sentido, outro estudo também revelou que mesmo frequentando o pré-natal, a mulher ainda chega ao último mês demonstrando déficit de conhecimento sobre alterações advindas da gravidez ${ }^{11}$. Portanto, é preciso o adequado e precoce acompanhamento no prénatal para que possam ser identificados os fatores de riscos aos quais as gestantes estão expostas facilitando o adequado manejo ${ }^{17}$, o que inclui o apoio à amamentação que contribua, inclusive, para o aumento das taxas de aleitamento materno e redução da morbimortalidade infantil.

Reforça-se, assim, a importância da atuação do enfermeiro como educador em saúde no puerpério, a partir das experiências e expectativas das mulheres, pois, dificuldades quanto técnicas e posições inadequadas para amamentação ainda são presentes, o que também justifica o fato das puérperas destacarem que as enfermeiras frequentemente orientam sobre o posicionamento para amamentar o bebê e cuidados com as mamas no Alojamento Conjunto.

Ademais, além da execução de práticas educativas, os profissionais precisam avançar para o processo avaliativo do ensino aprendizagem de modo a privilegiar o conteúdo social, cultura e os valores dos educandos ${ }^{18}$, no caso, as mulheres no que se referem as suas necessidades acerca da amamentação. 
Destaca-se que as puérperas nutrizes demonstraram interesse por diferentes formas de aprendizado, especialmente às estratégias visuais, que causam maior impacto por demonstrarem situações do aleitamento materno na prática. Tal achado condiz com um estudo que comprovou a eficácia do uso de simuladores realísticos de baixa fidelidade em orientações voltadas à puérperas, evidenciando melhora do manejo clínico da amamentação e redução do risco de insucesso no aleitamento materno ${ }^{19}$.

Por fim, evidencia-se que a prática educativa sobre aleitamento materno deve estar inserida no fazer dos profissionais de saúde, incluindo o enfermeiro, não somente no puerpério, mas do pré-natal ao pós-alta, seja em visitas domiciliares ou em consultas de retorno. Entretanto, há que se destacar que o processo de ensino-aprendizagem sobre essa temática não se restringe apenas ao contato com os profissionais, pois o ser humano aprende e ensina nas diferentes relações que estabelece nos ambientes sociais. Tal constatação precisa ser valorizada e resgatada na construção de práticas educativas contextualizadas.

O limite desse estudo é não saber se os bebês continuarão em aleitamento materno, motivo pelo qual se sugere novos estudos a fim de relacionar se os atores, os conteúdos e as práticas são eficazes na permanência do aleitamento materno exclusivo até os primeiros seis meses do bebê e complementar até dois anos de idade ou mais.

\section{CONCLUSÕES}

O estudo revelou que as mulheres da família são personagens importantes na construção dos saberes relativos ao aleitamento materno. Ademais, a atuação de enfermeiras, especialmente do hospital, também foi evidente, na medida em que todas as puérperas relataram terem participado, em algum momento, de orientações sobre temática junto a essa profissional.

Nas diferentes relações estabelecidas, as puérperas aprenderam sobre a importância da amamentação, qualidade do leite materno, posicionamento do bebê e manejo das mamas. $\mathrm{O}$ aprendizado foi mediado por experiências vividas de forma direta e no seio familiar, além de orientações, mediadas pelas estratégias verbais e demonstrativas por diferentes pessoas, profissionais de saúde ou não, com as quais interagiram.

Como todas as participantes estavam amamentando seus bebês, apenas duas de modo não exclusivo, observou-se boa adesão ao aleitamento materno. Nesse sentido, o estudo aponta para a relação entre o conhecimento de puérperas, construído nas suas trajetórias de vida, e a motivação para amamentar.

Conclui-se que orientar, apoiar e incentivar o aleitamento materno repercute de modo positivo no processo de ensino-aprendizagem das puérperas. Contudo, há que se avançar em ações educativas em saúde que partam do conhecimento prévio das mulheres e que não se restrinjam ao puerpério.

Assim, o presente estudo reforça a necessidade de criação e fortalecimento de estratégias educativas em saúde, com a inclusão da família, antes, durante e após o puerpério, a fim de contribuir para o aumento da prevalência do aleitamento 
materno. Sugere-se, ainda, que a equipe de saúde favoreça a ampliação dos conhecimentos sobre a temática, com a abordagem de diferentes aspectos sobre amamentação que sejam de interesse das mulheres e suas famílias.

Conflito de interesse: Os autores declaram que não houve conflitos de interesse.

\section{REFERÊNCIAS}

1. Brasil. Ministério da Saúde. Saúde da criança: aleitamento materno e alimentação complementar. 2nd ed. Brasília (DF): Ministério da Saúde; 2015. Disponível em: http://bvsms.saude.gov.br/bvs/publicacoes/saude crianca aleitamento materno cab23.pdf

2. Brasil. Ministério da Saúde. II Pesquisa de Prevalência de Aleitamento Materno nas Capitais Brasileiras e Distrito Federal. Brasília (DF): Ministério da Saúde; 2009. Disponível em: http://bvsms.saude.gov.br/bvs/ publicacoes/pesquisa prevalencia_aleitamento materno. pdf

3. Venâncio SI, Martins MCN, Sanches MTC, Almeida H, Rios GS, Frias PG. Análise de implantação da Rede Amamenta Brasil. Cad. Saúde Pública. 2013; 29(11): 2261-74. http://dx.doi.org/10.1590/0102-311x00156712

4. Soratto J, Pires DEP, Cabral IE, Lazzari DD, Witt RR, Sipriano CAS. A maneira criativa e sensível de pesquisar. Rev Bras Enferm. 2014; 67(6): 994-9. http://dx.doi.org/10.1590/0034-7167.201467061

5. Tong A, Sainsbury P, Craig J. Consolidated criteria for reporting qualitative research (COREQ): a 32-item checklist for interviews and focus groups. International Journal for Quality in Health Care. 2007; 19(6): 349-57. https://doi.org/10.1093/intqhc/mzm042

6. Fontanella BJB, Ronis MJL. Saturação teórica em pesquisas qualitativas: contribuições psicanalíticas. Psicol Estud. 2012; 17(1): 63-71.

http://dx.doi.org/10.1590/S1413-73722012000100008

7. Minayo MCS. O desafio do conhecimento. 12nd ed. São Paulo (SP): Hucitec; 2012.

8. Nakano AMS. O espaço social das mulheres e a referência para o cuidado na prática da amamentação. Rev. LatinoAm. Enfermagem. 2007; 15(2): 230-8. http://dx.doi.org/10.1590/S0104-11692007000200007

9. Batista KRA, Farias MCAD, Melo WSN. Influência da assistência de enfermagem na prática da amamentação no puerpério imediato. Saúde em Debate. 2013; 37(96): 1308.

10. Góes FGB, Rangel RO, Borges RLL. Práticas educativas do enfermeiro junto às puérperas sobre a amamentação. Rev enferm UFPE on Line. 2009; 3(1): 46-53.

https://doi.org/10.5205/1981-8963-v3i1a5700p43-53-2009
11. Barbosa LN, Santos NC, Moraes MAM, Rizzardi SD, Corrêa EC. Prevalência de práticas educativas acerca do aleitamento materno exclusivo em Cuiabá - MT. Esc Anna Nery. 2015; 19(1): 147-53. http://dx.doi.org/10.5935/1414-8145.20150020

12. Prates LA, Schmalfuss JM, Lipinski JM. Social support network of post-partum mothers in the practice of breastfeeding. Esc Anna Nery. 2015; 19(2): 310-15 http://dx.doi.org/10.5935/1414-8145.20150042

13. Freire P. Pedagogia da autonomia: saberes necessários à prática educativa. 43nd ed. São Paulo (SP): Paz e Terra; 2011.

14. Luna IF, Torres EA, Tamayo C, Vélez S, Ramírez MM, González C, et al. Uso de lãs tecnologías de información y comunicación para el cuidado del binômio maternofetal: revisión de tema. Med U.P.B. 2015; 34(2): 138-147.

15. Silva NMS, Waterkemper R, Silva EF, Cordova FP, Bonilha AL. Conhecimento de puérperas sobre amamentação exclusiva. Rev Bras Enferm. 2014; 67(2): 290-5. http://dx.doi.org/10.5935/0034-7167.20140039

16. Chaves AFL, Lima GP, Melo GM, Rocha RS, Vasconcelos HCA, Oriá MOB. Validation of a flipchart for promotion of self-efficacy in breastfeeding. Rev Rene. 2015; 16(3): 586-93. http://dx.doi.org/10.1590/S0103-21002013000600013

17. Moya-Plata D, Guiza-Salazar IJ, Mora-Merchán MA. Ingreso Temprano al Control Prenatal en una Unidad Materno Infantil. Rev Cuid. 2010; 1(1): 44-52. https://doi.org/10.15649/cuidarte.v1i1.73

18. Martínez JC. Practicas evaluativas del proceso de atención de enfermería: una visión de docentes y estudiantes. Rev Cuid. 2017; 8(1): 1459-75.

http://dx.doi.org/10.15649/cuidarte.v8i1.351

19. Fontoura-Abissulo CM, Silvino ZR, Ferreira HC. Validation of realistic simulators used for breastfeeding guidance: a quasi-experimental study. Online braz J Nurs. 2016; 15 (4): 599-604. http://dx.doi.org/10.17665/1676-4285.20165345 